\title{
Orfeu refletido ou a negação do mito Michele Gialdroni
}

$\mathrm{H}$ Á ALGO DE sombrio e anódino nos mitologemas que resistem ao tempo. Um excesso ou uma ausência de personalidade que tornam inconsistentes as fábulas do passado. A releitura contemporânea do mito atormenta a psicologia das personagens, por trazer algo de mais incerto e contraditório, mais próximo a nós. O preço pago pelas banalização dos arquétipos das pulsões humanas é a perda de seu fascínio. O mito torna-se estória, historieta, anedota. A troca das polaridades, por si elemento constitutivo do mito, torna-se estratégia de vulgarização. A narrativa $O$ senhor vai entender, de Claudio Magris, enunciada como um monólogo teatral de uma Eurídice moderna, é uma obra-prima de coerência nesse sentido. Mesmo atendo-se estritamente ao mitologema fundamental do amor perdido de Orfeu, não faz uma releitura do mito, não fornece uma nova chave de leitura universal. Consegue muito mais sujeitar o mito - reconhecibilíssimo, intacto - às exigências de uma estória particular, única, irrepetível, a estória do homem que escreveu essa narrativa.

O Orfeu de Magris é um artista inseguro e atrapalhado, que aprendeu com a amada Eurídice a viver no mundo, a dar o nó na gravata e a dizer as coisas certas na hora certa. E, naturalmente, as alegrias do sexo, pois, no jogo das polaridades, a Eurídice de $O$ senhor vai entender representa a concretude da vida, pelo menos aos olhos de Orfeu. Desde o início da narrativa, contudo, a voz que narra dirige seu memorial a um espectral "senhor Presidente", e encontra-se em um lugar, "a Casa”, imerso na penumbra, no qual mal se distinguem os contornos das coisas e das pessoas. Revelar a essência desse além tão incerto e indeterminado, no qual não são claras nem regras, nem estruturas e hierarquias significaria abandonar Orfeu ao desalento. De fato, o poeta, o cantor, afronta obstinadamente uma fatigante via-crúcis burocrática, irônica e dessacralizante, a fim de recuperar o equilíbrio da própria personalidade, que na ausência da companheira está destinada a desorientar-se, a perder-se em estórias inúteis, em gracejos vazios, no esquecimento de si mesmo de quem necessita do outro para reconhecer-se. A terrível revelação da falta de verdades absolutas, que perturbaria Orfeu para sempre e lhe secaria a veia artística, induz Eurídice a chamar o amado antes de sair ao ar livre, transgredindo as condições combinadas, e a decretar a separação definitiva.

Orfeu é o artista que precisa acreditar em algo certo, não só para criar, pela arte, mas para viver. Eurídice preocupase com o homem, o artista lhe é quase indiferente. O senhor vai entender não quer fornecer explicações sobre a relação de Orfeu e Eurídice como metáfora da criação artística: a atenção dada pelo século XX ao olhar de Orfeu, a atenção de Rilke e Blanchot, vem despistada. Desvanecem no nada do arbítrio as mil interpretações do gesto de Orfeu, do instante da separação da coisa amada, ao mesmo tempo inelutável e condenável, como experiência estética e fonte de inspiração. Desvanecem-se porque Orfeu olha para trás não por impaciência, temor ou curiosidade. Ou por sua firme vontade, como nas narrativas L'inconsolabile de Cesare 
Pavese (em Dialoghi con Leucò, 1947) ou Il ritorno di Euridice de Gesualdo Bufalino (em L'uomo invaso, 1986). É Eurídice que chama, é a voz firme e consciente de quem antes era sem rosto.

O primeiro a fazer Eurídice falar com extraordinária e afetada intensidade, no final do Oitocentos, foi um poeta consagrado, Robert Browning, que após longa e proveitosa estada na Itália, ao retornar à Inglaterra publicou os monólogos líricos de Dramatis Personae (1864). Nesta coletânea encontra-se a memorável alocução Eurydice to Orpheus, na qual Browning inverte os papéis mas não os conteúdos da relação e faz de Eurídice a amante apaixonada e impaciente até a inconsciência de si do grito final: "No past is mine, no future: look at me!". Contudo, só no início do Novecentos Eurídice encontra coragem para afirmar definitivamente sua presença e articular seu pensamento, um ponto de vista original seu, pelos versos de algumas poetisas anglo-saxônicas, a começar por uma protagonista da vanguarda literária dos primeiros decênios do século, Hilda Doolittle, a mítica H. D., pupila de Ezra Pound, que desde 1917, num estilo imagista despojado, faz que Eurídice denuncie, em primeira pessoa e com extraordinária clareza, o cego egoísmo de Orfeu: "So for your arrogance / and your ruthlessness / I have lost the earth". Uma tradição que continua no segundo pósguerra, com versos postos na boca de Eurídice por poetisas como a excêntrica aristocrata britânica Edith Sitwell, a escritora canadense Margaret Atwood, ativista dos direitos humanos, ou a norte-americana Jorie Graham, cujos poemas líricos são plenos de sugestões clássicas colhidas nos anos de juventude passados em Roma.

Considerando melhor, todavia, as razões do amor de Eurídice não podem ser as razões do amor de Orfeu. Se os efeitos da separação são os mesmos, dado que em definitivo a veia criativa de Orfeu está salva, é a inversão do ponto de vista que conta: o amor de Eurídice é todo terreno, carnal, e mal suporta a translação metafórica, a alegoria da impossibilidade de possuir o amado. Com frequência, a Eurídice novecentista permanece conscientemente no reino dos mortos, a Eurídice corrupta e corruptora do Orfen rei de Victor Segalen (1917), que Claude Debussy antes encomendara e depois evitou musicar, a sanguinária de Orfeu e Eurídice que o pintor Oskar Kokoschka escreveu em 1915, ferido no front galiciano, ou a triste e resignada do erótico Poema a Fumetti de Dino Buzzati de 1967: personagem já ligada ao Ínfero, que encontrou sua dimensão extraterrena, expressionisticamente glamorosa ou tristemente espectral. A voz que narra em $O$ senhor vai entender é, ao contrário, extraordinariamente livre na sua escolha. Não é afeiçoada à Casa, esse infinito asilo extraterreno no qual se consome em vã espera de encontros e acontecimentos decisivos, é somente por amor ao Orfeu cartorial que renuncia a voltar ao seu lado. Comportando-se assim não faz outra coisa senão renunciar ao mito, porque no mito não existe liberdade. Existem variações, talvez infinitas, mas não liberdade.

E Orfeu, afinal, o atrapalhado Orfeu de Magris? Deverá resignar-se à perda da amada, mas não terá nada de que se culpar. Aliás, saberá para sempre que a vida é outra coisa.

Mesmo em outro texto recente de Magris, o ambicioso romance Alla cieca (2005), são muitas as referências ao mito, que nesse caso permanece como tal. Eurídice assume traços bem mais estáticos, uma carranca de olhos esbugalhados que 
perscrutam o horizonte marinho, pressagiosos das futuras desgraças. Também Alla cieca se apresenta como um longo monólogo, complexo no entretecer de diferentes personalidades na voz do narrador, o velho comunista Salvatore Cippico, vítima de todas as desgraças das derivas ideológicas novecentistas e internado, não por nada, em um Centro de Saúde Mental. Mas logicamente a personalidade mais próxima a Orfeu não é a do pobre Cippico, tampouco a de um verdadeiro artista, mas antes a de um aventureiro com veleidades de escritor, o extraordinário personagem histórico Jorgen Jorgensen, marinheiro dinamarquês que ajudou a fundar a capital da Tasmânia, foi rei da Islândia por três semanas e terminou seus dias, entre prisão e miséria, na cidade que ele mesmo fundara. Portanto, também no romance está presente a intuição de uma Eurídice que sabe e de um Orfeu incompleto, inadequado, que a admira e a chama para conhecer verdades a ele vedadas. Mas em Alla cieca, em sintonia com a inspiração épica dessa narrativa coletiva confiada às vozes de sonhadores irredutíveis, fracassados e marginalizados pela história, o mito permanece intacto, permanece símbolo da aspiração humana ao melhor, do impulso criador que se torna biografia fantástica: Orfeu e Eurídice são chamados pelo nome. Aqui o ponto de vista é o do homem, mesmo nas cenas eróticas à beira-mar, tão semelhantes ao monólogo teatral no feminino. Eurídice é o nome de uma carranca muda e Jorgen Jorgensen pode afirmar: "Eu, abraçandome a ela, me salvei". Em O senhor vai entender, texto definitivo na sua depurada simplicidade, os nomes não comparecem jamais e o mito se desnuda do poder associativo, da sua função geradora, ficando somente uma referência, ao contrário de tanta literatura contemporânea que faz da condição de Eurídice a catalisadora de casos extraordinários, talvez de revelações cosmogônicas como nas Cosmicômicas de Italo Calvino (1965) e em A terra sob seus pés de Salman Rushdie (1999).

Essa voz que monologa é bem mais surpreendente por remeter ao teatro, ao percurso que tornou Eurídice sempre mais protagonista do palco, mas também sempre mais distante de Orfeu. Se se quiser prescindir das reconstruções puramente líricas da relação, é importante considerar a sequência de transposições do mito em ambientação contemporânea, como as desoladas estações de periferia de Euridice de Jean Anouilh (1941) ou o profundo sul intolerante dos Estados Unidos em Orpheus descending de Tennessee Williams (1957). Comum a esse tipo de texto é o sentido de trágica inelutabilidade do destino. Outra tradição forte é a da comédia, da estória recontada numa vertigem de encontros surreais e reviravoltas. Da ópera bufa de Orfen no inferno de Jacques Offenbach (1858), que joga com a traição de Eurídice (quase uma tópica novecentista) até a poesia surreal de Cocteau, que dedicará à figura uma peça de sucesso, Orfen, de 1926, e boa parte de sua produção cinematográfica. É exatamente na tradição satírica e grotesca que no curso dos séculos a personagem de Eurídice assumiu maior importância. Se excluirmos as exegeses medievais de Boécio e de seu Orfeu cristianizado do terceiro livro de De consolatione philosophiae, que vê em Eurídice a personificação da tentação terrena e do mal, é nos textos parodísticos do barroco espanhol que encontramos pela primeira vez uma Eurídice que chama voluntariamente Orfeu para que a missão dele falhe e ela não volte a ser explorada por um marido 
opressor e aborrecido. As polêmicas suscitadas pelo rebuscado poema gongórico Orfeu, do sevilhano Juan de Jáuregui, de 1624 , deram origem a uma intensa produção satírica em que Eurídice se torna uma sagaz moça do povo, capaz de recusar com firmeza a intervenção do pedante poeta: "Pues si contigo ba de ser / Yo me resuelvo a quedarme". A inversão de papéis é dessacralização grotesca, mas também inversão surreal e, no Orfeu cinematográfico de Jean Cocteau, de 1949, é Eurídice quem primeiro olha o poeta e espera ser correspondida. Olha pelo espelhinho retrovisor do mesmo Rolls Royce no qual Orfeu ouve pelo rádio misteriosas ordens em forma de livre associação poética, ordens de morte que o fascinam a ponto de confundir o amor por Eurídice com o encanto da dama de negro. Também o Orfeu de Cocteau não é senhor da situação, e na verdade não o é nem mesmo Eurídice.

Numa peça contemporânea, a brilhante Euridice da jovem dramaturga norteamericana Sarah Ruhl (2003), a mulher é definitivamente protagonista do mito e reverte as conotações semânticas, passando de metáfora da paixão erótica para apologia do amor filial. A Eurídice de Ruhl é extraordinariamente vital e o além que ela afronta é cheio de surpresas: chove nos elevadores e se sofre de repentinas desmemórias. A linguagem é seca, o espaço do não dito beckettiano é ocupado pela ironia da abordagem pós-moderna, da citação pop. Quando essa Eurídice decide permanecer no além para fazer companhia ao pai, quem sofre as consequências é Orfeu, personagem reduzido a seu papel de amante unidimensional segundo uma inversão perfeita da relevância da individualidade. Deslocando o foco de Orfeu para Eurídice, o enredo do drama passa da relação da morte com a arte e com a paixão amorosa para a dificuldade de viver uma condição recordando outra: aceitar sua nova vida significaria para Eurídice imergir no rio e esquecer definitivamente os sentimentos do passado. A Eurídice de Magris, ao contrário, mesmo ocupando todo o espaço do palco com a extraordinária força de sua voz e de sua carnalidade, o faz para falar-nos do outro, para falar-nos de Orfeu, que se torna personagem complexo e carismático, verossímil na sua incompletude. Semelhante ao próprio escritor que o criou ou, mais ainda, à sua caricatura. Na Itália, outros autores tentaram levar à cena um Orfeu novecentista, burguês como no drama policialesco Lamento de Orfeu de Valentino Bompiani (1961), ou ironicamente inepto como na ópera em um ato Orfeu viúvo de Alberto Saviano (1950). Nenhum deles, porém, tivera o despudor de colocar-se na pele de Orfeu, coisa possível somente a Magris no jogo irônico da ridicularização amorosa e desdenhosa do seu papel, por obra de sua parte mais sã e vital, a parte de si que é interpretada por Eurídice.

$\mathrm{O}$ além de $O$ senhor vai entender, essa imensa Casa de Repouso, é descrito através dos grossos óculos de um Ernesto Sabato, percorrido com o passo incerto de um interno saído das páginas de Robert Walser, com o risco de perder pouco a pouco a consciência de si, de morrer congelado sem nem ao menos se aperceber disso, como aconteceu ao próprio escritor suíço na noite de Natal de 1956, durante uma caminhada pelos arredores do sanatório no qual se recuperava havia mais de vinte anos. A Casa da narrativa pretende ser um espaço real, mesmo que diferente do mundo dos ruídos, da política cultural e das pessoas. Assemelha-se de algum 


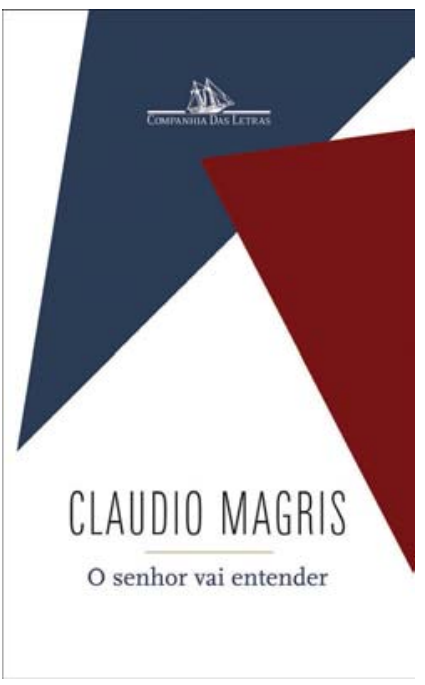

MAGRIS, Claudio. O senhor vai entender. Trad. Maurício Santana Dias. São Paulo: Cia. das Letras, 2008.

modo ao mundo ctônico no qual Calvino faz andar o seu Qfwfq, alter ego de Orfeu, antes que uma erupção do Vesúvio o impeça de ganhar a odiosa superfície terrestre para se confrontar com as cores, os ruídos e a confusão do mundo. O próprio Magris, comentando suas fontes de inspiração, fala de uma perturbadora "experiência do limiar", sentida ao entrar numa peculiar casa de repouso triestina, na qual fora encontrar uma velha conhecida de seus leitores, a vitalíssima, cáustica e desordenada vovó Anka, que acompanha o narrador de Danúbio (1989) em seu giro entre a Sérvia e a Romênia, do Banato à Transilvânia, até as fronteiras da Bucovinia. E falando precisamente da antiga capital da Bucovinia, Czernowitz, Magris se detém no mais conhecido de seus filhos, aquele que considera o último grande poeta órfico, Paul Celan, sempre em busca da palavra mágica e secreta, do verdadeiro nome das coisas, para além das redes de convenções da comunicação. Celan, contudo, não foi poupado pela terrifican- te vacuidade da verdade última das coisas, a insuportável revelação do nada, exatamente o desprazer que a voz de $O$ senhor vai entender quer poupar ao seu desgraçado companheiro.

Cada vez que entrava no asilo triestino em que vovó Anka estava internada, Magris era tomado da sensação de que o tempo se dilatava, de que hierarquias e afetos seguiam lógicas outras, desconhecidas. Mesmo a noção de espaço devia ser reformulada naquela casa de repouso, espécie de universo paralelo no interior do nosso mundo, no qual era possível imaginar novas noções de dentro e de fora. Tanto que, em $O$ senhor vai entender, no mesmo espaço da Casa, em seu interior, sem que se volte a viver no mundo, existem ruas povoadas de sombras, cursos d'água e paredes rochosas: toda uma desfocada cenografia infernal, quase como se fosse o nobre castelo dantesco, tendo no seu interior espaços arquitetônicos e espaços naturais que permitem aos grandes espíritos, entre eles Orfeu, mover-se livremente. Um nobre castelo degradado a sanatório kafkiano por espíritos evanescentes, não mais concebível em sua totalidade. E é surpreendente que ao descrever esse ambiente fantástico o escritor faça mais referência a uma experiência vivida - mesmo se num certo sentido se trate de fato da experiência da impossibilidade de vivenciar concretamente - do que a sugestões literárias e culturais. Referências que condicionam a experiência psicológica e cognitiva do limiar e só indiretamente uma representação que se quer especialmente autêntica das vazias arquiteturas extraterrenas.

Magris, portanto, não reelabora nem reescreve o mito ou faz uma releitura: é a sua negação. Uma estória individual e irrepetível, pois baseada em decisões au- 
tônomas e livres dos protagonistas, que preserva o mitologema mas o impede de articular-se em mito de valor universal. A inversão do ponto de vista está no sacrifício amoroso da protagonista, que se condena à morte eterna por não revelar ao poeta a verdade última de uma vasta $\mathrm{e}$ vã incerteza. Não é a Eurídice vingadora, amada pelas escritas femininas do Novecentos, a que, reconhecido o egoísmo de Orfeu, recusa superar o limiar para ser apenas coadjuvante. A Eurídice de Magris dessacraliza e desmonta o mito, encontrado quase ao acaso na tentativa de dar voz a uma experiência concreta, ela não se submete às suas regras e exorciza seu impulso criador. A mulher declara desesperadamente seu amor, mas afirma também a vontade de ficar sozinha, de ser ela mesma na solidão, até mesmo no diálogo com o destinatário de suas palavras, aquele Presidente inacessível, imperscrutável, embora onipresente, tão próximo a Deus. Então as palavras de Eurídice, mesmo aquelas em que sente mais forte a nostalgia da carne, tornam-se sintomas incompreendidos do erotismo místico de uma mulher que substituiu a devoção do êxtase pela simples ataraxia, e sente que deve prestar contas ao próprio Deus, que poderia não compreender sua frieza. Talvez o leitor não deva acreditar inteiramente nas palavras de Eurídice, pronunciadas em alta voz em um teatral monólogo. Talvez os seus motivos estejam em outro lugar, em um espaço de pulsões de difícil intuição, uma rebelião não dita difícil de conciliar com a estrutura antropológica arquetípica da fantasia que costumamos atribuir à essência do mito. $\mathrm{O}$ desejo de não ser envolvido é um impulso à recusa do mito. Eurídice não se decide por este ou aquele lado. A experiência da Casa despertou o desejo, a necessidade de solidão que distancia Eurídice da paixão de Orfeu, da matriz dionisíaca do rito de amor que é tradicionalmente ligada ao nascimento da poesia. Falando da ilha que foi cenário dos momentos mais intensos da paixão deles, termina dizendo: "Mesmo sozinha, mesmo sem ele, ficaria feliz em dar uma caminhada por aqueles lados". Mesmo amando o poeta, Eurídice, em definitivo, tem nostalgia do mundo, não de Orfeu e das pressões a que ele a sujeitaria, uma vez novamente juntos. Entre sacrifício de amor, rebelião individual e desejo de solidão, essa Eurídice se aventurou numa terra incógnita, mais longínqua dos originários montes da Trácia que o próprio reino de Perséfone.

Michele Gialdroni é doutor em Literatura Italiana e adido cultural da Itália em Stuttgart, Alemanha. Estudou línguas e literaturas modernas na Itália e na Alemanha. Ensinou literatura e italiano nas universidades de Tübingen, Stuttgart, Roma, Tre e Passau. É coautor do livro Lipari 1929. Fuga dal confino (Laterza, 2009). O autor agradece de coração ao escritor pelas luminosas indicações fornecidas em relação ao seu Lei dunque capirà. @ - gialdroni@virgilio.it.

Tradução de Naoju Kimura. 